\title{
Prophylaxis of Heterotopic Ossification of the Hip
}

\author{
Systematic Review and Meta-Analysis
}

\author{
Patrick Vavken MD, MSc, Lorenzo Castellani MD, \\ Thomas P. Sculco MD
}

Received: 20 October 2008/ Accepted: 29 May 2009/Published online: 11 June 2009

(C) The Association of Bone and Joint Surgeons $\mathbb{R} 2009$

\begin{abstract}
Heterotopic ossification (HO) is a potentially severe, if infrequent, complication in hip surgery, and uncertainty exists regarding whether to use NSAIDs or radiation in its prevention. Thus, we systematically reviewed the literature in MedLine, EMBASE, CINAHL, and the Cochrane Controlled Trial Register and, after ruling out publication bias and data heterogeneity, performed a meta-analysis of randomized, controlled trials to assess effectiveness and complications of NSAIDs and radiation in the prevention of $\mathrm{HO}$. We identified nine studies reporting on effectiveness and complications including a total of 1295 patients. The pooled risk ratio for the effectiveness in HO prevention was 0.96 (95\% confidence interval, 0.88-1.06) and was independent of the type of surgery (THA or open reduction and internal fixation). There was no association with gender, age, length of followup, or year of publication. The risk ratio for associated
\end{abstract}

Each author certifies that he or she has no commercial associations (eg, consultancies, stock ownership, equity interest, patent/licensing arrangements, etc) that might pose a conflict of interest in connection with the submitted article.

This work was performed at Children's Hospital of Boston.

P. Vavken $(\bowtie)$

Department of Orthopedic Surgery, Children's Hospital Boston,

Harvard Medical School, 300 Longwood Avenue, Enders 1016,

Boston, MA 02115, USA

e-mail: patrick.vavken@childrens.harvard.edu

L. Castellani

Department of Orthopaedic Surgery and Traumatology, Istituto Clinico S. Ambrogio, Milano, Italy

T. P. Sculco

Department of Orthopaedic Surgery, Hospital for Special

Surgery, New York, NY, USA complications was 0.79 (95\% confidence interval, 0.451.41), and, again, was independent of the aforementioned factors. We found no evidence for a statistically significant or clinically important difference between NSAIDs or radiation in preventing $\mathrm{HO}$.

\section{Introduction}

Severe HO is a potentially serious complication in hip surgery $[1,12,23]$. Although most patients are asymptomatic, two articles including 10,826 subjects from 37 studies suggest $\mathrm{HO}$ may be associated with substantial compromise of function and range of motion even at low grades, although most studies report high functional levels except at the highest grades using various outcome measures [10, 22]. However, it is not surprising a couple studies recommend prevention in patients undergoing hip surgery $[3,9,10]$. NSAIDs and radiation, two distinct treatment options, are the mainstays of $\mathrm{HO}$ prevention, both of which are reportedly effective for that purpose [9, 10, 19]. Numerous randomized, controlled trials comparing NSAIDs and radiation in the prevention of $\mathrm{HO}$ have been published, but their results are inconsistent $[2,5,18,25,28]$. A systematic review published in 2004 focused on differences in effectiveness of NSAIDs and radiation in HO prophylaxis, but that study did not include all of the currently available evidence and did not consider safety patterns in its analysis [25]. Furthermore, the related costs of these treatments have been described in only one study, and the cost-effectiveness of these two approaches has not yet been studied [29].

We therefore systematically reviewed and did a metaanalysis of the current evidence comparing NSAIDs and radiation in the prevention of $\mathrm{HO}$ after hip surgery to test two hypotheses. Our first hypothesis was that there was no 
difference in the effectiveness of these treatment options. Our second hypothesis was that there was no difference in complication rates. Both hypotheses included adjustment for potential confounding by variables, such as type of procedure, length of followup, origin and year of publication, and age and gender of included patients.

\section{Materials and Methods}

To test our two hypotheses, we performed a meta-analysis of randomized and quasirandomized controlled trials comparing NSAIDs and radiation to pool data on effectiveness and complications of these treatments. We searched the electronic databases MEDLINE, EMBASE, CINAHL (Cumulative Index of Nursing and Allied Health), and CCTR (Cochrane Controlled Trial Register) online for ("ossification" OR "heterotopic") AND ("radiotherapy" OR "radiation" OR "irradiation") AND "hip", using these terms as keywords and exploded MeSH terms without restrictions in language or year of publication. We included only prospective, controlled, randomized or quasirandomized studies directly comparing NSAIDs with radiation in human subjects. Eligible interventions were all total hip replacements and open reduction and internal fixations of fractures about the hip, with a minimum followup of 6 months to ensure enough time for bone formation. We included both procedures as most information regarding $\mathrm{HO}$ prophylaxis is published for these. We included the resulting potential for heterogeneity in our assessment. Eligibility of studies was assessed independently and in duplicate (PV, LC) and cross-checked to avoid errors. Disagreement was resolved by discussion or, if necessary, with the help of the senior author (TPS). The bibliographies of all included studies were reviewed for additional relevant studies. From the included studies, data concerning study design, patient characteristics, and the end points incidence of $\mathrm{HO}$ and complications were abstracted in duplicate (PV, LC) and cross-checked.

Our search strategy generated 135 studies online and six by citation tracking. In cases of overlapping data, studies were merged as far as possible; completely overlapping studies were excluded. Finally, nine studies were included. These studies were published in either German or English between 1995 and 2001 (Table 1; Fig. 1). Six studies reported on primary THA $[4,15,18-20,28]$ and three on open reduction and internal fixation (ORIF) of acetabular fractures [5, 21, 27]. Martini et al. [20] reported specifically on the perioperative adverse events in patients receiving NSAIDs and radiation. All other studies reported on the

Table 1. Patient characteristics and treatment regimens in the included studies*

\begin{tabular}{|c|c|c|c|c|c|c|c|c|}
\hline \multirow[t]{2}{*}{ Study } & \multirow{2}{*}{$\begin{array}{l}\text { Mean age } \\
\text { (years) }\end{array}$} & \multirow{2}{*}{$\begin{array}{l}\text { Female } \\
(\%)\end{array}$} & \multirow[t]{2}{*}{ Procedure } & \multicolumn{2}{|l|}{ NSAIDs } & \multicolumn{2}{|c|}{ Radiation } & \multirow{2}{*}{$\begin{array}{l}\text { Mean followup } \\
\text { (months) }\end{array}$} \\
\hline & & & & Number & Regimen & Number & Regimen & \\
\hline Martini et al. [20] (1995) & 58 & 46 & THA & 25 & $\begin{array}{l}\text { Diclofenac } \\
\quad 3 \times 50 \mathrm{mg} / 6 \text { weeks }\end{array}$ & 25 & $\begin{array}{l}5 \times 2 \text { Gy } \\
\quad(\leq \text { POD } 5)\end{array}$ & $\begin{array}{l}\text { Directly } \\
\text { postoperative }\end{array}$ \\
\hline $\begin{array}{l}\text { Bremen-Kühne et al. [4] } \\
\text { (1997) }\end{array}$ & & 44 & THA & 31 & $\begin{array}{l}\text { Indomethacin } \\
3 \times 25 \mathrm{mg} / 10 \text { days }\end{array}$ & 19 & $\begin{array}{l}1 \times 6 \mathrm{~Gy} \\
\quad(\leq \mathrm{POD} 4)\end{array}$ & 12 \\
\hline \multirow[t]{3}{*}{ Knelles et al. [18] (1997) } & 67 & 64 & THA & 296 & $\begin{array}{l}\text { Indomethacin } \\
2 \times 50 \mathrm{mg} / 7 \text { days }\end{array}$ & 289 & $\begin{aligned} 4 & \times 3 \mathrm{cGy} \\
& (\leq \text { POD } 5)\end{aligned}$ & 12 \\
\hline & & & & & $\begin{array}{l}\text { Indomethacin } \\
2 \times 50 \mathrm{mg} / 14 \text { days }\end{array}$ & & $\begin{array}{l}1 \times 7 \text { cGy } \\
\quad(\leq \text { POD } 5)\end{array}$ & \\
\hline & & & & & $\begin{array}{l}\text { Aspirin } \\
\quad 3 \times 750 \mathrm{mg} / 14 \text { days }\end{array}$ & & $\begin{array}{l}1 \times 5 \mathrm{cGy} \\
\quad(\leq \text { POD } 5)\end{array}$ & \\
\hline Sell et al. [28] (1998) & 61 & 42 & THA & 77 & $\begin{array}{l}\text { Diclofenac } \\
\quad 3 \times 50 \mathrm{mg} / 3 \text { weeks }\end{array}$ & 77 & $\begin{array}{l}3 \times 3.3 \mathrm{~Gy} \\
\quad(\leq \text { POD } 3)\end{array}$ & 6 \\
\hline Kölbl et al. [19] (1998) & 65 & 50 & THA & 54 & $\begin{array}{l}\text { Diclofenac } \\
2 \times 75 \mathrm{mg} / 14 \text { days }\end{array}$ & 46 & $\begin{array}{l}1 \times 7 \mathrm{cGY} \\
\text { preoperative }\end{array}$ & 6 \\
\hline Kienapfel et al. [15] (1999) & 64 & 57 & THA & 55 & $\begin{array}{l}\text { Indomethacin } \\
\quad 2 \times 50 \mathrm{mg} / 42 \text { days }\end{array}$ & 49 & $\begin{array}{l}1 \times 600 \mathrm{cGy} \\
\quad(\leq \text { POD 3.2) }\end{array}$ & 18 \\
\hline Moore et al. [21] (1998) & 45 & 30 & ORIF & 39 & $\begin{array}{l}\text { Indomethacin } \\
\quad 3 \times 25 \mathrm{mg} / 6 \text { weeks }\end{array}$ & 33 & $\begin{aligned} 1 & \times 800 \mathrm{cGy} \\
& (\leq \mathrm{POD} 2)\end{aligned}$ & 12 \\
\hline Schafer et al. [27] (2000) & & & ORIF & 37 & $\begin{array}{l}\text { Indomethacin } \\
\quad 3 \times 25 \mathrm{mg} / 6 \text { weeks }\end{array}$ & 43 & "low dose" & 16 \\
\hline Burd et al. [5] (2001) & 43 & 30 & ORIF & 72 & $\begin{array}{l}\text { Indomethacin } \\
\quad 3 \times 25 \mathrm{mg} / 6 \text { weeks }\end{array}$ & 78 & $\begin{array}{r}1 \times 800 \mathrm{cGy} \\
\quad(\leq \text { POD } 3)\end{array}$ & 14.5 \\
\hline
\end{tabular}

* There is a considerable heterogeneity of treatments in patients having THA compared with patients having ORIF; POD = postoperative day; ORIF $=$ open reduction and internal fixation. 


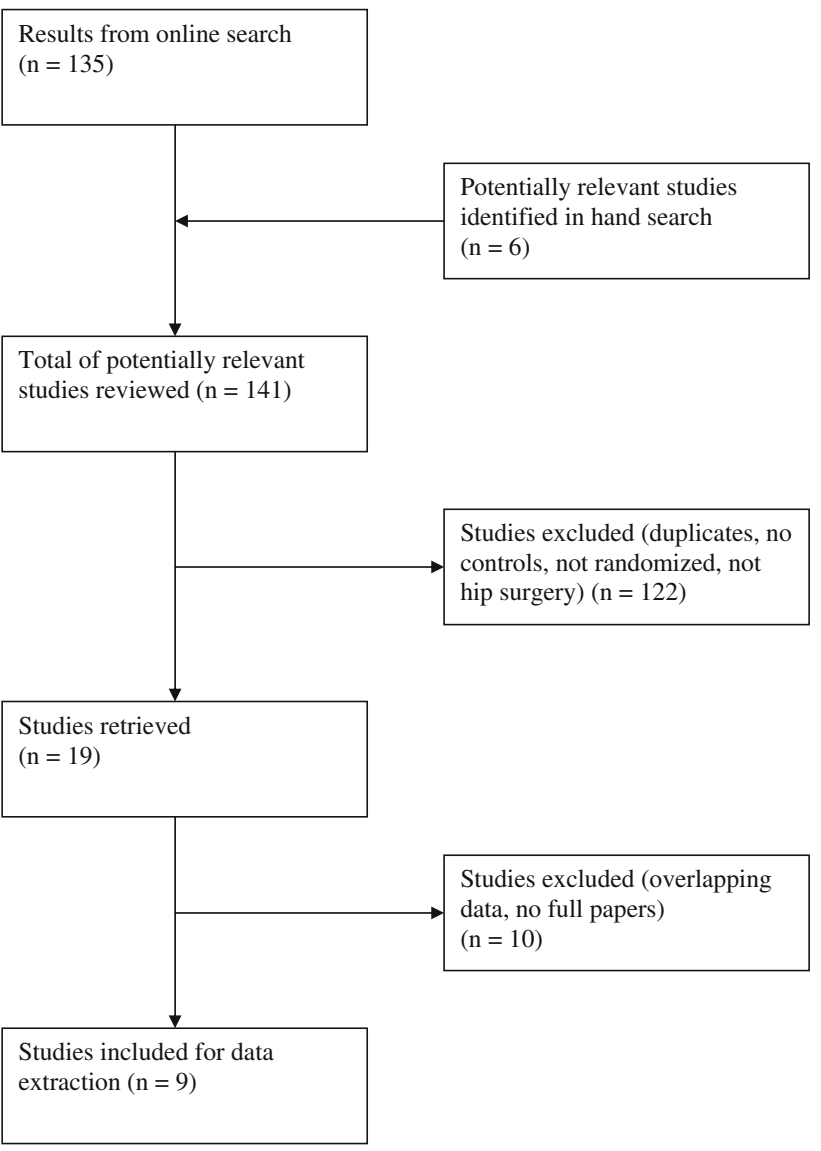

Fig. 1 A flowchart illustrates the trial flow.

incidence of $\mathrm{HO}$ as a primary end point. Four studies mentioned side effects [15, 18, 19, 28], whereas Burd et al. [5] reported they observed no side effects. Only one study referred to the intention-to-treat principle [5]. Data regarding the incidence of $\mathrm{HO}$ despite prophylaxis could be extracted from eight studies [4, 5, 15, 18, 19, 21, 27, 28], and a total of 1295 patients could be included (661 who received NSAIDs versus 634 who received radiation). Five trials provided data for analysis of complications associated with treatments $[15,18-20,28]$. Generally, data regarding complications were reported less systematically than data for effectiveness, but we were able to extract information for 992 patients (507 who received NSAIDs versus 485 who received radiation). The reported complications included, but were not exclusive to, dyspepsia and other gastrointestinal problems, wound dehiscence, protracted wound secretion, tissue necrosis, and systemic complications, such as fever, elevated erythrocyte sedimentation rate, and leukocytosis.

High study quality and validity of findings among primary studies are crucial for a meta-analysis. We assessed these parameters using the Jadad scale [7], which ranges from 0 points (poorest result) to 5 points (best result), attributing points on how randomization, blinding, and attrition were addressed. The mean Jadad score for the included trials was 1.8 points $(95 \%$ confidence interval [CI], 0.9-2.8 points). Another important problem that jeopardizes the validity of a meta-analysis is publication bias, or so-called file-drawer bias, which means bias attributable to unidentified or unpublished studies. These studies often remain unpublished in a drawer because they are negative studies, ie, their results are not significant, causing an erroneously high proportion of positive studies, ie, those with significant results, among published studies $[14,24]$. Publication bias among the included studies was assessed graphically using funnel plots and mathematically using Egger's weighted regression [8]. The presence of between-study heterogeneity was qualified by Cochrane's $\mathrm{Q}$ test, using a $\mathrm{p}$ value of $10 \%$ to adjust for the low power of this test in small samples, and quantified using the $\mathrm{I}^{2}$ index [11]. We presumed year of publication, type of procedure, distribution of age and gender, length of followup, and continent of origin were potential sources of between-study heterogeneity, ie, confounders in the relationship between treatment option and effectiveness or complications. To assess these potential sources, metaregressions were performed [30, 31]. To pool data, random-effects models using the DerSimonian-Laird method were constructed [6]. Such models postulate the observed heterogeneity between studies in a meta-analysis is attributable to normally distributed individual effects around a common effect. This assumption was assessed graphically in the forest plots.

All results from the meta-analysis are presented as risk ratios (RRs) with 95\% CIs. The level of significance for combined estimates was set at 5\%. All calculations were performed using Intercooled STATA ${ }^{\circledR} 10$ (StataCorp LP, College Station, TX).

\section{Results}

We found no difference in effectiveness of preventing $\mathrm{HO}$ between NSAIDs and radiation at a RR of $1.2(95 \% \mathrm{CI}$, $0.8-1.8 ; \mathrm{p}=0.474$ ) (Fig. 2). There was no evidence $(\mathrm{p}=0.186)$ for publication bias among the eight studies from which these data were extracted. Between-study heterogeneity was high $(\mathrm{p}<0.001)$ for studies of $\mathrm{HO}$ after THA, but not for studies of HO after ORIF ( $p=0.490$ ) of the hip. Heterogeneity among the former, however, was caused almost entirely by the study by Kölbl et al. [19]. Assessing potential sources of heterogeneity, we found no associations with gender $(p=0.760)$, age $(p=0.852)$, year of publication $(p=0.784)$, length of followup ( $p=0.506)$, or origin of the study $(p=0.576)$. However, focusing on THA only, there was an association between 

RR of HO despite prophylactic treatment in nine studies comparing NSAIDs and radiation, stratified by type of surgery. The diamonds give the $95 \%$ CI of the subgroup and the overall pooled estimate. There is no difference in effectiveness in patients receiving $\mathrm{HO}$ prevention after THA or ORIF. The heterogeneity, ie, incomplete overlap, of the individual study estimates, represented by horizontal lines with boxes corresponding to sample size, in the THA stratum can be seen.
Fig. 2 This forest plot shows the

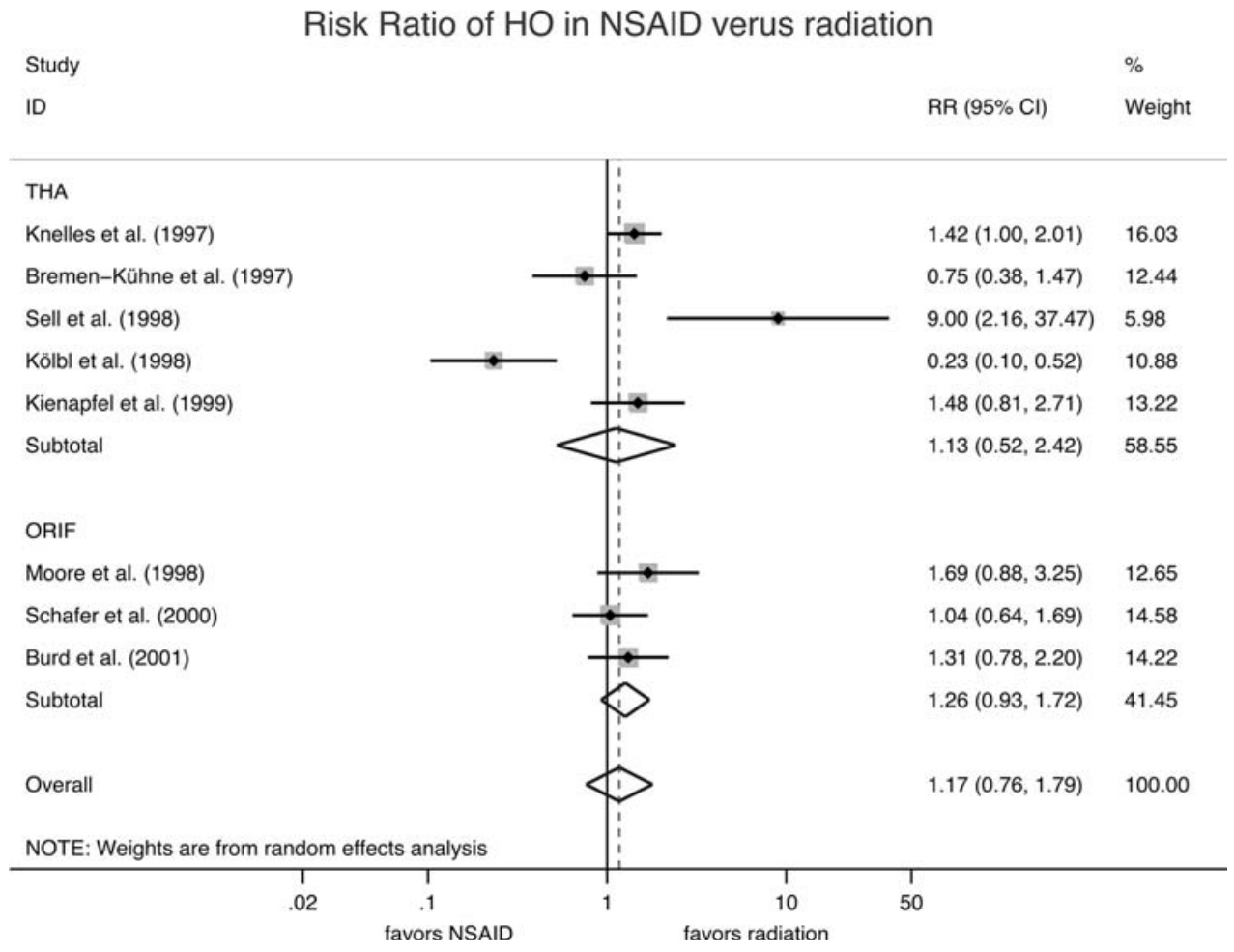

Fig. 3 This forest plot represents the pooling of RRs of complications. In contrast to the forest plot for effectiveness (Fig. 2), it seems the two studies at the top and the two studies at the bottom are more similar to each other than to all others (see text). Finally, the $95 \%$ CI of the pooled RR is quite wide and includes values ranging from an almost $60 \%$ risk decrease to a $40 \%$ risk increase. Although not statistically significant, the extreme values of the $95 \%$ CI included values potentially of clinical importance.

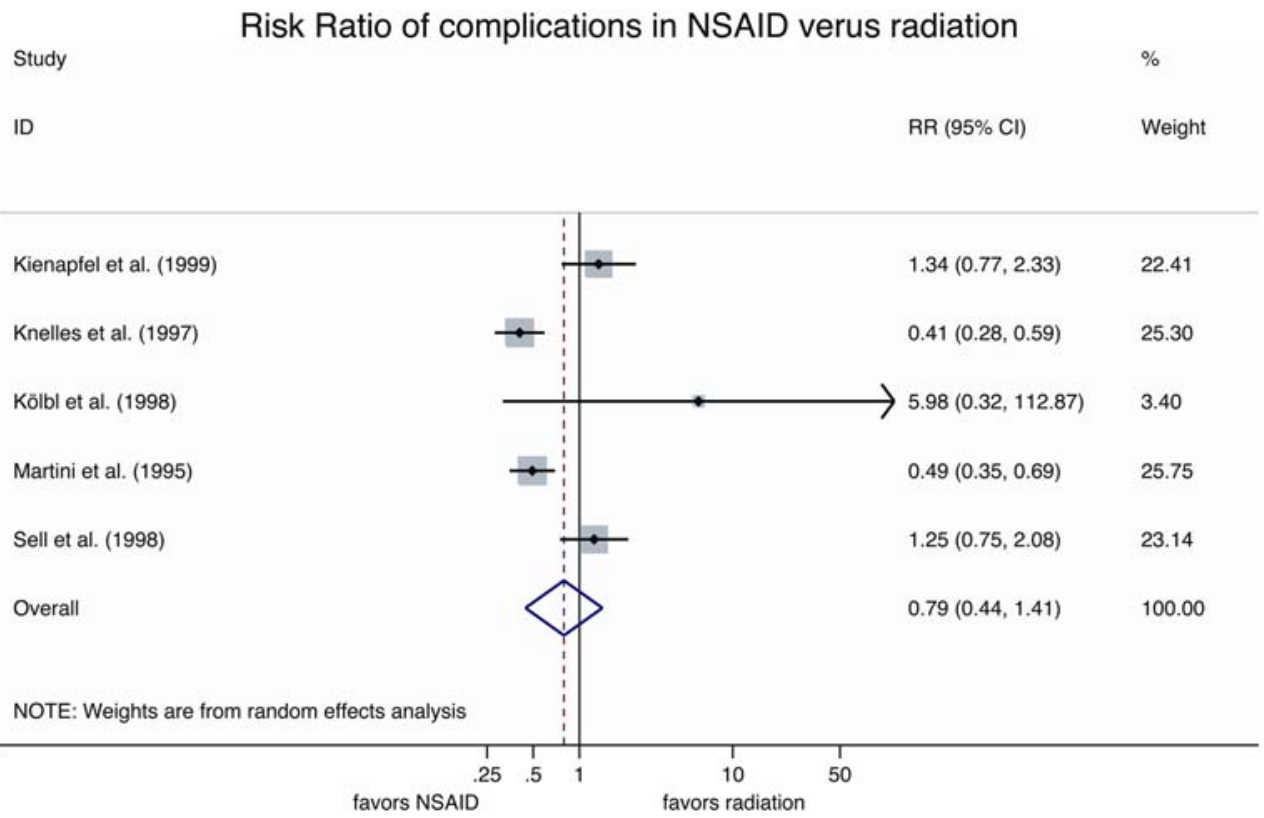

age and the RR of HO ( $\mathrm{p}=0.028)$, consistent with a small reduction in risk with age. Surprisingly, there was no difference ( $p=0.576$ ) between RRs of HO for THA and ORIF, suggesting equal effectiveness of prophylactic treatments in both procedures. This finding supports our decision to include THA and ORIF in our analysis.

The pooled RR for complications between NSAIDs and radiation was 0.793 (95\% CI, 0.5-1.4), suggesting no evidence $(\mathrm{p}=0.431)$ for a difference in the risk of complications (Fig. 3). There was no indication $(\mathrm{p}=0.366)$ of publication bias among the papers from which these data were extracted. Heterogeneity, however, was high ( $\mathrm{p}<0.001$ ), but again was caused mostly by the study by Kölbl et al. [19]. Also, there seemed to be some clustering of RRs in the studies by Martini et al. [20], Knelles et al. [18], Sell et al. [28], and Kienapfel et al. [15], but there was 
no evidence for influence by any of the studied potential confounders.

\section{Discussion}

$\mathrm{HO}$ is a well-known complication after hip surgery, but it can be avoided with prophylactic treatment such as NSAIDs or radiation. The individual efficacies of both major options in HO prevention, NSAIDs and radiation, have been confirmed repeatedly, yet the question remains which prophylactic treatment to use. It was the objective of our study to synthesize in a meta-analysis the current evidence for effectiveness and complications in the prevention of $\mathrm{HO}$ of the hip with NSAIDs or radiation.

Our study has limitations. Like any meta-analysis and systematic review, it builds exclusively on reported data, which are not necessarily complete or accurate. Our systematic review is susceptible to poor study quality of the reviewed reports and thus low validity among the primary studies; however, we saw convincing values on the Jadad scale for all included studies. Clinical heterogeneity might be an additional limitation. We decided to include studies of THA and ORIF after hip fractures in our analysis, although these procedures clearly are clinically different. However, we found no unequivocal evidence that different mechanisms cause $\mathrm{HO}$ in these two sets of patients but rather found evidence for similar effectiveness, suggesting a strong similarity in the underlying biology.

Pooling the evidence from the existing literature, we found no differences in the effectiveness of radiation or NSAIDs in the prevention of HO. Also, the $95 \%$ CI of the RR was too narrow to suggest a potential for important changes in new, even larger studies. There was no difference in effectiveness based on the type of procedure, ie, THA or ORIF, which is biologically plausible, as in both cases osseous and tissue trauma initiate spreading and differentiation of progenitor cells from the bone marrow. Apparently, inhibition of this process by NSAIDs or radiation is independent of the source of trauma. There was high heterogeneity between studies focusing on treatment effectiveness in patients having THA, but plotting of the study effects suggested a normal distribution of individual effects around a common effect; thus, a random-effects model could be constructed without jeopardizing the validity of pooled estimates [6]. Furthermore, it seemed the brunt of the heterogeneity was introduced by the study by Kölbl et al. [19], which is not surprising considering patients in this study were treated with preoperative radiation, whereas all other patients were treated postoperatively. Nevertheless, we performed meta-regressions to study potential sources of between-study differences [30]. As mentioned above, type of surgery was not associated with differences in effectiveness, meaning $\mathrm{HO}$ prevention was equally effective in patients undergoing THA or ORIF. We assessed the origin of the studies as a source of heterogeneity to account for regional preferences in treatments but found no association. Also, we found no association of effectiveness with length of followup, ruling out oversight of late-onset ossification. However, we did identify considerable differences in treatment regimens among patients having THA, which are a very plausible source of clinical heterogeneity (Table 1). Concerning the optimal NSAID regimen, however, there are ample published studies on dosage and duration, and it seems even only week-long treatments at fairly low dosages produce convincing results $[2,18]$. Such optimized regimens, in turn, have been proven to cause no increase in the incidence of gastrointestinal bleeding or other gastrointestinal problems, the most common argument against NSAIDs [10]. Our findings are supported by a smaller systematic review by Pakos and Ioannidis [25] focusing only on the efficacy of NSAIDs and radiotherapy, which presents similar findings. However, their study showed a trend-wise difference, yet of small size, favoring radiation in the prevention of Brooker Grades 3 and 4, building on the assumption that higher Brooker grades cause more problems. Yet this assumption was refuted by Neal [22] in a study of 10,826 individuals. Therefore, we did not perform subgroup analyses by grade of $\mathrm{HO}$.

Our analysis of complications associated with NSAIDs or radiation showed no differences. Yet the $95 \% \mathrm{CI}$ of the RR was somewhat wider than that in the analysis of effectiveness and would allow anything from a $40 \%$ increase to a $56 \%$ decrease. Despite the lack of statistical significance, such changes are clinically important. Additional studies will help to narrow this range of uncertainty. The interpretation of the forest plot suggests the studies of Martini et al. [20], Knelles et al. [18], Sell et al. [28], and Kienapfel et al. [15] are more similar to each other than to other studies. We found no variable systematically associated with this clustering, thus suggesting confounding, but the description of complications among these studies was similar enough to have potentially caused such a distribution. When these results are interpreted, complications, as mentioned above, were reported less systematically than effectiveness, ie, different complications were studied using more than one scale. Also, complications depended on the details of the treatment regimen, such as dosage and duration, which were nonuniform across studies (Table 1). We were unable to find data on potential long-term complications of radiation or NSAIDs. However, the existence and clinical meaning of suggested potential long-term complications, such as soft tissue or osseous malignancies attributable to radiation [16, 17] or prosthetic loosening attributable to NSAIDs [26], are more than questionable, 
especially considering the prohibitively long latencies of such events at the average age of most patients undergoing hip surgery. A recent study reported no increase in implant migration after 5 years in patients who had received NSAIDs or radiation to prevent HO [13].

We found no evidence for a statistically significant or clinically important difference in the effectiveness of NSAIDs versus radiation in the prevention of HO. We also found no difference in risk, but a fairly wide 95\% CI suggests future studies might show an important effect. Although these risk ratios were not statistically significant, there is an undisputable difference in the costs of these treatments. A recent study by Strauss et al. building on Medicare data from 2007 calculated the costs of administering NSAIDs as \$19.71 compared with 45-times higher costs of radiation therapy (\$898.55) [29]. Our findings suggest NSAIDs are an effective and safe option to prevent a potentially severe complication after hip surgery. As there are virtually no data regarding quality of life with these treatments, future studies might address this problem, perhaps in association with cost-utility analyses.

\section{References}

1. Back DL, Smith JD, Dalziel RE, Young DA, Shimmin A. Incidence of heterotopic ossification after hip resurfacing. ANZ $J$ Surg. 2007;77:642-647.

2. Birrell F, Lohmander S. Non-steroidal anti-inflammatory drugs after hip replacement. BMJ. 2006;333:507-508.

3. Board TN, Karva A, Board RE, Gambhir AK, Porter ML. The prophylaxis and treatment of heterotopic ossification following lower limb arthroplasty. J Bone Joint Surg Br. 2007;89:434-440.

4. Bremen-Kühne R, Stock D, Franke C. [Indomethacin: short-term therapy vs. single low dosage radiation for prevention of periarticular ossifications after total hip endoprosthesis] [in German]. Z Orthop Ihre Grenzgeb. 1997;135:422-429.

5. Burd T, Lowry K, Anglen J. Indomethacin compared with localized irradiation for the prevention of heterotopic ossification following surgical treatment of acetabular fractures. J Bone Joint Surg Am. 2001;83:1783-1788.

6. DerSimonian R, Laird N. Meta-analysis in clinical trials. Control Clin Trials. 1986;7:177-188.

7. Duval S, Tweedie R. A nonparametric "trim and fill" method of accounting for publication bias in meta-analysis. J Am Stat Assoc. 2000;95:89-98.

8. Egger M, Davey Smith G, Schneider M, Minder C. Bias in metaanalysis detected by a simple, graphical test. BMJ. 1997;315: 629-634.

9. Fransen M, Anderson C, Douglas J, MacMahon S, Neal B, Norton R, Woodward M, Cameron ID, Crawford R, Lo SK, Tregonning G, Windolf M, Group HC. Safety and efficacy of routine postoperative ibuprofen for pain and disability related to ectopic bone formation after hip replacement surgery (HIPAID): randomised controlled trial. BMJ. 2006;333:519.

10. Fransen M, Neal B. Non-steroidal anti-inflammatory drugs for preventing heterotopic bone formation after hip arthroplasty. Cochrane Database Syst Rev. 2004;3:CD001160.
11. Higgins JP, Thompson SG, Deeks JJ, Altman DG. Measuring inconsistency in meta-analyses. BMJ. 2003;327:557-560.

12. Higo T, Mawatari M, Shigematsu M, Hotokebuchi T. The incidence of heterotopic ossification after cementless total hip arthroplasty. J Arthroplasty. 2006;21:852-856.

13. Ince A, Sauer U, Wollmerstedt N, Hendrich C. No migration of acetabular cups after prophylaxis for heterotopic ossification. Clin Orthop Relat Res. 2007;461:125-129.

14. Johnson RT, Dickersin K. Publication bias against negative results from clinical trials: three of the seven deadly sins. Nat Clin Pract Neurol. 2007;3:590-591.

15. Kienapfel H, Koller M, Wüst A, Sprey C, Merte H, EngenhartCabillic R, Griss P. Prevention of heterotopic bone formation after total hip arthroplasty: a prospective randomised study comparing postoperative radiation therapy with indomethacin medication. Arch Orthop Trauma Surg. 1999;119:296-302.

16. Kim JH, Chu FC, Woodward HQ, Huvos A. Radiation induced sarcomas of bone following therapeutic radiation. Int J Radiat Oncol Biol Phys. 1983;9:107-110.

17. Kim JH, Chu FC, Woodward HQ, Melamed MR, Huvos A, Cantin J. Radiation-induced soft-tissue and bone sarcoma. Radiology. 1978;129:501-508.

18. Knelles D, Barthel T, Karrer A, Kraus U, Eulert J, Kolbl O. Prevention of heterotopic ossification after total hip replacement: a prospective, randomised study using acetylsalicylic acid, indomethacin and fractional or single-dose irradiation. $J$ Bone Joint Surg Br. 1997;79:596-602.

19. Kölbl O, Knelles D, Barthel T, Raunecker F, Flentje M, Eulert J. Preoperative irradiation versus the use of nonsteroidal antiinflammatory drugs for prevention of heterotopic ossification following total hip replacement: the results of a randomized trial. Int J Radiat Oncol Biol Phys. 1998;42:397-401.

20. Martini F, Sell S, Reize P, Jani R, Küsswetter W. Perioperative side effects of preventative measures against heterotopic ossification: diclofenac versus irradiation. Aktuelle Rheumatol. 1995; 20:61-65.

21. Moore KD, Goss K, Anglen JO. Indomethacin versus radiation therapy for prophylaxis against heterotopic ossification in acetabular fractures: a randomised, prospective study. J Bone Joint Surg Br. 1998;80:259-263.

22. Neal B. Effects of heterotopic bone formation on outcome after hip arthroplasty. ANZ J Surg. 2003;73:422-426.

23. Neal B, Gray H, MacMahon S, Dunn L. Incidence of heterotopic bone formation after major hip surgery. ANZ J Surg. 2002;72: $808-821$.

24. Okike K, Kocher MS, Mehlman CT, Heckman JD, Bhandari M. Publication bias in orthopaedic research: an analysis of scientific factors associated with publication in the Journal of Bone and Joint Surgery (American Volume). J Bone Joint Surg Am. 2008; 90:595-601.

25. Pakos E, Ioannidis J. Radiotherapy vs. nonsteroidal anti-inflammatory drugs for the prevention of heterotopic ossification after major hip procedures: a meta-analysis of randomized trials. Int $J$. Radiat Oncol Biol Phys. 2004;60:888-895.

26. Persson PE, Nilsson OS, Berggren AM. Do non-steroidal antiinflammatory drugs cause endoprosthetic loosening? A 10-year follow-up of a randomized trial on ibuprofen for prevention of heterotopic ossification after hip arthroplasty. Acta Orthop. 2005;76:735-740

27. Schafer SJ, Schafer LO, Anglen JO, Childers M. Heterotopic ossification in rehabilitation patients who have had internal fixation of an acetabular fracture. J Rehabil Res Dev. 2000;37:389393.

28. Sell S, Willms R, Jany R, Esenwein S, Gaissmaier C, Martini F, Bruhn G, Burkhardsmaier F, Bamberg M, Küsswetter W. The 
suppression of heterotopic ossifications: radiation versus NSAID therapy - a prospective study. J Arthroplasty. 1998;13:854-859.

29. Strauss JB, Chen SS, Shah AP, Coon AB, Dickler A. Cost of radiotherapy versus NSAID administration for prevention of heterotopic ossification after total hip arthroplasty. Int $J$ Radiat Oncol Biol Phys. 2008;71:1460-1464.
30. Thompson SG. Why and How Sources of Heterogeneity Should Be Investigated. Ed 2. London, England: BMJ Publishing Group; 2001.

31. Vavken P, Culen G, Dorotka R. Management of confounding in controlled orthopaedic trials: a cross-sectional study. Clin Orthop Relat Res. 2008;466:985-989. 